\title{
ASPECTOS DA VIDA DE GERHART HAUPTMANN
}

Em comemoração ao seu vigésimo-quinto aniversório do falecimento.

PETRA BOSSMANN ROMANUS

Gerhart Hauptmann, notável poeta e dramaturgo alemão: nasceu a 15 de novembro de 1862 em Ober-Sazbrunn, Silésia.

Visto que seus antecedentes, que exerciam a profissão de tecelões ou hoteleiros, eram oriundos dessa mesma região, recebeu o jovem poeta, desde a infância, as primeiras impressões da pobreza dos tecelões silesianos. Ele se achava vocacionado para a escultura, trabalhou neste ramo em Roma e teve a experiência com a antiguidade romana a qual foi a causa de sua metamorfose para tornar-se um poeta.

Após seu regresso da Itália, continuou os já anteriormente co. meçados estudos sôbre Filosofia, Arqueologia, História Grega e Literatura, em Berlim, entrando em contato com os círculos naturalistas e escreveu ai suas primeiras obras que significavam uma inovação para Literatura, Teatro e Sociologia. Compara-se-o com Ibsen; entretanto logo o supera de muito. Com suas obras-primas, os dramas "Vor Sonnenaufgang" (1889 - Antes da Aurora) e "Die Weber" (1892 - Os Tecelōes), tornou-se o símbolo do Naturalismo, peças que foram recebidas com aplausos, mas também com protestos, e demonstraram a exatidão da descrição do ambiente, a técnica de sua arte dramática, a precisão de sua linguagem, a compreensão da psique de seus personagens. Após o sucesso de "Die Weber" seguiu-se a comédia "Der Biberpelz" (1893 - A Pele de Castor) a qual pertence às melhores comédias do teatro alemão.

Como peça naturalista escreveu ainda a tragicomédia "Die Ratten" (Os Ratos), que tem como palco o nordeste de Berlim, e cuja ação se desenrola numa habitação coletiva.

Nas tragédias "Fuhrmann Henschel" (1898 - Cocheiro Hens. chel) e "Rose Bernd" (1903), êle determinou de modo naturalista, mais os caráteres do que as situações, mas também aqui o personagem não é o executor, mas sim o induzido conforme a doutrina filosófica dominante do determinismo. 0 mundo erudito esperava o 
prosseguimento de Hauptmann no estilo naturalista, mas para surprêsa de todos surge a obra "Hanneles Himmelfahrt" (1893 - A Ascenção de Hannele), a qual na forma e na descrição da miséria segue a linha naturalista, porém na rima, nas visōes de uma pobre criança, nas aparições celestes é, todavia, simbolista. As obras "Die versunkene Glocke" (1896 - O Sino Afundado), uma tragédia sôbre a vida de um artista, e a lenda simbólica da cabana de vidro da bela região montanhosa silesiana, denominada "Und Pippa tanzt" (E Pippa dança), tendem para o estilo romântico-visionário.

Hauptmann passou de naturalista para romântico, tornou-se ora analítico, ora fantasista, uma metamorfose atrós da qual estava escondido um ser cheio de compaixão, um modelador de destinos humanos, com o dom de dar forma plástica ao humano e expressão ao sobrenatural.

As fontes dêste vigor eram os sentimentos humanitário, religioso e social, a pátria silesiana, com os quais êle alimentou tôda a sua obra 1) em prosa, dramática, líricá e autobiográfica.

Após estadia em Zurique, Dresden, Leipzig e Berlim, Hauptmann retornou à terra natal e se radicou definitivamente em Agnetendorf.

Em 10 de agôsto de 1901, instalou-se no Wiesenstein, o qual, com o decorrer dos anos tornou-se "lugar de peregrinação" do mundo literário. Com isto, como êle próprio afirmou: "Reencontrei minha pátria". Numa carta sem data dirigida a Marie Hauptmann escreveu: "Eu batizei esta casa aqui de "Wiesenstein". Por um nome para a casa de Dresden meditei até agora em vão. Este aqui foi dado pelas "pedras do campo" que já estavam situadas no terreno e possuiam êste nome antes..." 2)

Na obra "Buch der Leidenschaft" (Livro da Paixão) encontramos sôbre Wiesenstein o seguinte trecho:

1) Prosa: "Der Bahnwärter Thiel" (O Guardalinha Thiel), "Der Narr in Christo Emanuel Quint" (Emanuel Quint, O Louco em Cristo, "Der Ketzer von Soana" (OO Herege de Saana), "Die Insel der grossen Mutter" (A llha da grande mäe), "Der Apostel", (O Apóstolo), "Atlantiz". Dramas: "Das Friedensfest" (A Festa da paz). "Einsame Menschen" (Homens solitários), "Kollege Crampton" (Colega Crampton), "Florian Geyer", "Michael Kramer", "Der arme Heinrich" 10 pobre Henrique), "Elga", "Ghiselda", "Gabriel Sehillings Flucht" (A Fuga de Gabriel Schilling), "Der Bogen des Odysseus" ( $O$ areo de Odisséu), "Der weisse Heiland" 10 Salvador branco), "Dorothea Angermann", "Die goldene Harfe" (A Harpa dourada), "Iphigenie in Aulis", "Agsmemnons Tod" (A Morte de Agamemnon), "Elektra", "Iphigenle in Delphi".

AUTOBRIOGRAFICA: "Griechischer Frühling" (Primavera Grega), "Buch der Laidenschaft" (Livro da Paixäo). "Im Wirbel der Berufung" (No Redemoinho da vocaçāol, "Dat Abentever meiner Jugend" (A Aventura de minha mocidade).

2) Gerhart Hauptmann, Leben und Werk. Gadächinisausstellung zum 100.

Geburststag, Sivitgant, 1962, pág. 134. 
..... O telhadc está coberto, as telhas foram melhor fixadas. A casa em cima de seus pilares salientes parece poder fazer frente aos demônios da montanha que sempre contra ela investem. O que a tôrre do castelo não pode excluir, o que ela em sua sombria gran. deza exprime, e, até intensifica, é o cósmico. Eu não conheço casa e lugar, onde o cósmico estivesse tão poderosamente presente...

Na casa até que há bastante animação, animação nāo sòmente feita por duendes ou espíritos aldravos, mas também graças a Deus por outros, de categoria superior. Assim por exemplo, pelo gênio da música, o qual Anja liberta com seu violino.

Todos os bons espíritos louvam o Senhor nesta casa e assim louvo eu todos os bons espíritos dentro dela. São muitos dêles e alegramo-nos com êste alarido. Estes bons espíritos não só sobrevivem a tôdas as intempéries desta selvagem, caprichosa e instável natureza cujas manifestaçōes de violência quase não a deformam, mas são êles que permitem que nenhuma das formosuras da casa passe despercebida... ${ }^{3}$ )

Uma outra ciłação sôbre o "Wiesenstein" diz o seguinte:

"Eu construi minha casa em cima desta colina exatamente por causa dêste panorama. As montanhas não iriam me atrair, não tivesse eu esta bela vista. A Alemanha é a tôrre da qual eu vejo o mundo, e como eu adapto o estilo da minha casa e de meus quartos à paisa. gem que me cerca, tento eu também, quando estou no estrangeiro, ampliar espiritualmente a minha pátria e o algo que ainda the falta, procuro incorporá-lo e outro tanto modificá-lo. Assim, eu reconheço na minha pátria o mundo e no mundo a minha pátria. Ambos se in. fluenciam mùtuamente, infiltram-se um ao outro, aperfeiçoam o quadro, como o vale completa a montanha e a montanha o vale..." 4)

Em Wiesenstein, Hauptmann festejou seu octogésimo aniversário, em plena 2." Guerra Mundial. Após ter assistido à destruição de Dresden e a derrota da Alemanha, 0 ancião pronunciou antes de seu falecimento em 6 de junho de 1946, as palavras: "Estou eu ainda em minha casa?"

Uma outra localidade que está muito ligada pelo destino à vida e obra de Hauptmann é a llha Hiddensee, a qual êle visitou pela pri-

3) Gerhart Hauptmann: Das gesammelte Werk. Erste Abteilung. Zwöiffer Band. Buch der Leidenschaft. S. Fischer Verlog. Berlin 1942. Pdg. 388.

4) Joseph Chopiro, Gespräche mit Gerhart Haupimann. Berlim 1932. Em: Gerhart Hauptmann, Leben und Werk. Gedichtnisaustellung zum 100. Geburtstag. Stutigart, 1962, p6g. 1351 
meira vez em 1855. Nas poesias "Mondscheinlerche" 5) (Cotovia de noite de luar) e "Die Insel" o) (A Ilha) êle exprime o seguinte sôbre Hiddensee:

\section{Mondscheinlerche}

Mondschein liegt um Meer und Land

dämmerig gebreitet;

in den weissen Dünensand

Well' auf Welle gleitet.

Unaufhörlich bläst das Meer

eherne Posaunen;

Roggenfelder, segenschwer,

leise wogend raunen.

Wiesenfläche, Feld und Hain

zaubereinsam schillern;

badend hoch im Mondenschein

Mondscheinlerchen triliern.

Die Insel

Hier, wo mein Hans steht, wehte einst niedriges Gras:

ums Herz Erinnerung weht, wie ich dereinst

mit Freunden hier sass.

Wir waren zu drei'n,

vor Jahrtausenden mag es gewesen sein.

Es war einsam hier,

tief, tief!

So waren auch wir.

Verlassenheit über der Insel schlief.

Dann kam der Lärm,

ein buntes Geschwärm:

entbundener Geist, verdorben, gestorben zu allermeist.

Und nun leben wir in fremdmächtiger Zeit, verschlagen wiederum in Verlassenheit.

In meines Hauses stillem Raum

herrscht der Traum.

5) Escrita a 29 de iulho de 1885 em Hiddensee. Em: Gerhart Haupimann: Das gesammelte Werk. Erste Abteilung I. Band. Das Bunte Buch. Gedichte. Pág. 103.

6) Gorhart Haupimann, Leben und Werk. Gedāchtnisausstellung zum 100. Geburtstag, Stuttgart, 1962, pog. 185. 
Sendo sua pátria silesiana seu mundo montanhoso, assim também foi Hiddensee, banhado pelas ondas do Mar Báltico, a estação de veraneio de singular significado para a sua produtividade literária.

"Esta claridadel Este emanar mundo e poderoso da luzl Além disso a liberdade para peregrinar sôbre relvado sem vereda. A tudo isso o sabor salgado sôbre os lábios. $O$ até as lágrimas comovente bramido do mar... Este intenso, radiante majestoso o qual pōe em movimento a ressaca." 7)

Sôbre a retidão de caráter de Hauptmann, mostra-nos um interessante incidente ocorrido entre êle e Thomas Mann o qual se encontrava em "Haus am Meer' em Hiddensee no ano de 1924. Narra Thomas Mann ${ }^{8}$ ) ter encontrado seu amigo Hauptmann cedo na praia, tendo êste já os cabelos molhados após seu banho de mar. Perguntou-lhe Mann, como estava a água, que é comumente fria neste balneário. Respondeu-lhe Hauptmann: “Regular, apenas um tanto quente. "Isto causou surprêsa em T. Mann o qual retrucou: "Isto é novidade! Então tanto melhor", e seguiu sua caminhada. Instantes depois veio Hauptmann ao seu encalço e explicou-lhe tratar-se de uma brincadeira. T. Mann explica esta reação de Hauptmann com a seguinte conclusão:... "Ele tinha-me pregado uma peça e temia uma espécie de choque, se eu entrasse na água pensando que estivesse quente. Eu jamais esquecerei êste comovente remorso de uma brincadeira tão inocente..."

Numa saudação de Maxim Gorki encontra-se o seguinte sôbre Hauptmann: ... "Hauptmann, um poeta, que sentiu profundamente o trágico da vida, não deixa de ser um idealista e de pregar à humanidade a tão necessária fé na vitória da razão e da beleza-valiosa é esta sua contribuição para a humanidade! Nada une os homens tão fortemente como a ciência e a arte - Hauptmann contribuiu muito para a grandiosa obra pela união da humanidade numa única grande família..." E mais adiante encerrando a sua saudação: ... Viva a vida, viva a arte! Viva Hauptmann e a Democracia que o gerou! ${ }^{9}$ )

A 28 de julho de 1946, ao nascer do sol, encontrou Hauptmann no cemitério do mosteiro de Hiddensee seu último jazigo. Margarete Hauptmann, sua segunda espôsa, depositou terra natal do Wiesenstein sôbre seu sarcófago.

7) Gerhant Hauptmann, Leben und Werk, Gedächinisausstellung zum 100.

Geburtstag. Stuttgart, 1962, p6́g. 180.

8) Em: Reden und Aufsälze, Fronkfurt, 1960. Auszug aus: Gerhart Hauptmann, Leben und Werk. Gedächtnisousstellung zum 100. Geburtstag. Stuttgart, 1962, pros. 181/182.

9) Gerhart Hauptmann, Leben u. Werk, Stuttgart, 1962, pág. 190. 
O extinguir-se de um grande poeta e agraciada vida humana não foi assistido pelo mundo naqueles conturbados dias de seu passamento. Porém seu brilho ressurgirá sempre que a humanidade redescobrir a mensagem que emana da obra de Hauptmann. 